\title{
Reduced glomerular function in rheumatoid arthritis
}

\author{
H. C. BURRY \\ Keat's House, Guy's Hospital, London, S.E.1
}

It has long been known that a proportion of patients with rheumatoid arthritis die in uraemia. Apart from amyloid deposition, which has been recognized as a complication for over a century, there has been considerable doubt whether rheumatoid disease affects the kidney.

The investigations of Sørensen (1960), Bulger, Healey, and Polinsky (1968), Richter (1942), and Heidelmann, Huth, and Koch (1956) have confirmed that the glomerular filtration rate (GFR) is commonly reduced, but opinion differs whether this is due to rheumatoid disease or whether it represents the end-results of the long-continued ingestion of anti-inflammatory and analgesic drugs.

The present survey was designed to examine this problem in more depth.

\section{Methods and material}

A total of 100 cases was admitted to the study, but three were subsequently excluded because of inadequacy of information, leaving 97 completely documented individuals. It was intended to exclude any patients with history of pre-existent upper renal tract disease, but as it happened no such cases were encountered. There was therefore no selection, the criteria for inclusion being definite or classical rheumatoid arthritis (as defined by the American Rheumatism Association) of more than 1 year's duration. There is no reason to suppose that the group includes an undue number of severely affected individuals. A full history was obtained with particular reference to duration of arthritis, previous renal disease, and past and present drug therapy. Full physical examination was performed, the presence or absence of subcutaneous rheumatoid nodules was noted, and blood pressure was recorded. $X$ rays of the hands and feet were examined for erosions.

Various aspects of renal function were studied but the results here reported relate particularly to investigations of the GFR. The endogenous creatinine clearance test was used to quantitate the GFR because of its convenience and reliability within accepted limits. In a number of cases, to test the accuracy of the results, the GFR was also estimated by means of the $\mathrm{Cr}^{51}$-labelled EDTA clearance test. Good correlation was seen, although results with the latter were rather higher in the presence of marked impairment of function.
Correlation was sought between low creatinine clearance and other evidence of renal disease such as amyloid, pyelonephritis, and hypertensive renal disease. In 25 cases with marked abnormalities an intravenous pyelogram was performed and in eleven a percutaneous renal biopsy was obtained.

\section{Therapy}

Retrospective quantitation of analgesic consumption is notoriously difficult, because of variation in intake from day to day and month to month and vagaries of the patient's memory, so that only approximate estimates can be obtained. However, it is possible to classify consumption into broad categories, and for the purpose of this survey the following groups were delineated:

\section{(1) SALICYLATES OR SALICYLATE-CONTAINING COMPOUND ANALGESICS}

(i) None or occasional only.

(ii) Less than 3 grammes salicylate daily for at least 6 months.

(iii) More than 3 grammes salicylate daily for at least 6 months.

(2) GOLD

(i) None.

(ii) One or more complete courses, or course terminated because of toxic effects.

(3) CORTICOSTEROIDS

(i) None.

(ii) Less than $7.5 \mathrm{mg}$. prednisolone (or equivalent) daily, or higher dose for less than 6 months.

(iii) At least $7.5 \mathrm{mg}$. prednisolone or equivalent daily for more than 6 months.

From the information thus collected, it has been possible to correlate glomerular function, with on the one hand severity and duration of the disease, and on the other various forms and combinations of drug therapy.

\section{Characteristics of the study group}

Of the total of 97 patients, 25 were male and 72 female. As expected the majority ( 80 per cent.) were between the ages of 40 and 69 years (range 19 to 78 ; mean 53). The duration of disease varied from 1 to 38 years (mean 9.7). 76 patients had an erosive arthritis, 65 had titres of rheumatoid factor 
in excess of $1: 8$ as shown by the sheep cell agglutination test, and in 33 subcutaneous rheumatoid nodules were observed. Arteritic lesions were not seen in any patients nor did any show evidence of neuropathy. The only systemic manifestations encountered were one case each of cardiomyopathy and fibrosing alveolitis.

\section{Results}

Fig. 1 shows the distribution of clearance values for the group. In 49 patients ( 41 female and 8 male) the creatinine clearance was less than $80 \mathrm{ml} . / \mathrm{min}$. In the Tables those with a clearance of less than $80 \mathrm{ml}$./ min. are designated 'abnormal'.

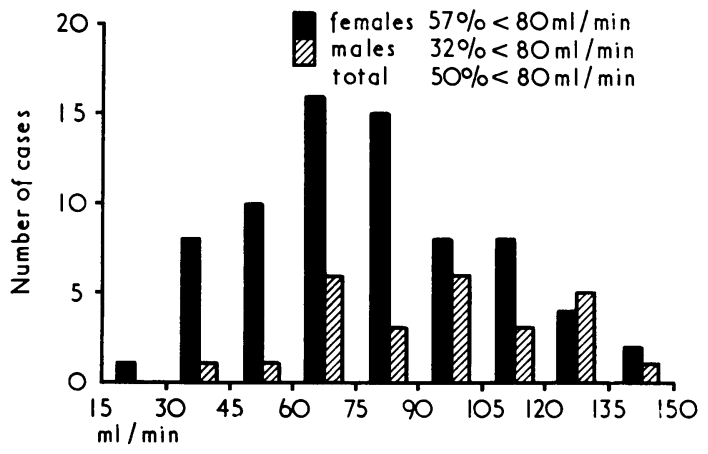

FIG. 1 Creatinine clearance, by sex

The expected correlation between age and reduced function was seen (Fig. 2), but there was no correlation between glomerular function and duration of disease or diastolic blood pressure.

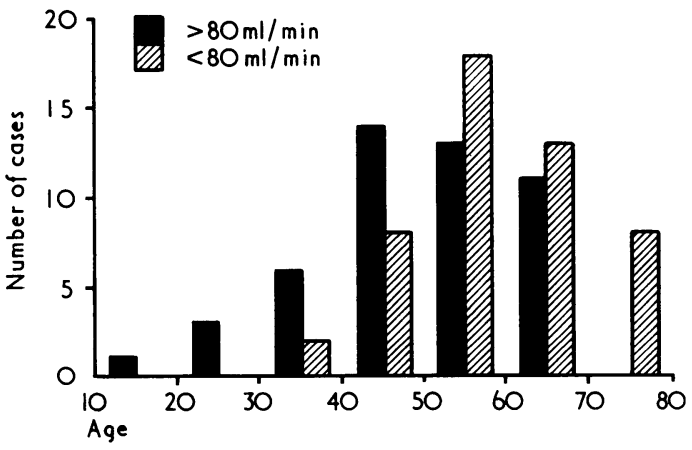

FIG. 2 Creatinine clearance, by age

Patients in whom the disease was characterized by the presence of articular erosions were shown to have poorer glomerular function (Table I) and this difference was not explained by age or sex. When females alone were considered, the incidence of low clearance values in patients with erosive arthritis was even greater- 65 per cent. compared with 21 per cent. in those without erosions ( $P<0 \cdot 01)$.

No correlation was seen between the presence in the serum of rheumatoid factor in titres in excess of $1: 8$
Table I Erosions and creatinine clearance

\begin{tabular}{|c|c|c|c|c|}
\hline \multirow[t]{3}{*}{ Erosions } & \multirow{3}{*}{$\begin{array}{l}\text { Mean age } \\
(y r s)\end{array}$} & \multicolumn{3}{|c|}{ Creatinine clearance } \\
\hline & & \multirow[t]{2}{*}{ Normal } & \multicolumn{2}{|c|}{ Abnormal } \\
\hline & & & No. & Per cent. \\
\hline $\begin{array}{l}\text { Present } \\
\text { Absent }\end{array}$ & $\begin{array}{l}54 \cdot 6 \\
50 \cdot 5\end{array}$ & $\begin{array}{l}33 \\
15\end{array}$ & $\begin{array}{r}43 \\
6\end{array}$ & $\begin{array}{l}57^{*} \\
29\end{array}$ \\
\hline
\end{tabular}

* $\mathrm{P}<0.05$.

and creatinine clearance (Table II), but a trend to poorer function was seen in patients with subcutaneous nodules (Table III).

Table II Serology and creatinine clearance

\begin{tabular}{|c|c|c|c|c|}
\hline \multirow{3}{*}{$\begin{array}{l}\text { Serological } \\
\text { findings }\end{array}$} & \multirow{3}{*}{$\begin{array}{l}\text { Mean age } \\
(y r s)\end{array}$} & \multicolumn{3}{|c|}{ Creatinine clearance } \\
\hline & & \multirow[t]{2}{*}{ Normal } & \multicolumn{2}{|c|}{ Abnormal } \\
\hline & & & No. & Per cent. \\
\hline $\begin{array}{l}\text { Positive } \\
\text { Negative }\end{array}$ & $\begin{array}{l}54 \cdot 4 \\
49 \cdot 9\end{array}$ & $\begin{array}{l}31 \\
17\end{array}$ & $\begin{array}{l}34 \\
15\end{array}$ & $\begin{array}{l}52 \\
47\end{array}$ \\
\hline
\end{tabular}

Table III Subcutaneous nodules and creatinine clearance

\begin{tabular}{|c|c|c|c|c|}
\hline \multirow[t]{3}{*}{ Nodules } & \multirow{3}{*}{$\begin{array}{l}\text { Mean age } \\
(y r s)\end{array}$} & \multicolumn{3}{|c|}{ Creatinine clearance } \\
\hline & & \multirow[t]{2}{*}{ Normal } & \multicolumn{2}{|c|}{ Abnormal } \\
\hline & & & No. & Per cent. \\
\hline $\begin{array}{l}\text { Present } \\
\text { Absent }\end{array}$ & $\begin{array}{l}52 \cdot 5 \\
53 \cdot 4\end{array}$ & $\begin{array}{l}12 \\
36\end{array}$ & $\begin{array}{l}21 \\
28\end{array}$ & $\begin{array}{l}67^{*} \\
44\end{array}$ \\
\hline
\end{tabular}

$0.1>P>0.05$.

Studies of drug therapy (Table IV) showed that there was no decrease in function with increasing dosage with salicylates, nor was there a trend concealed by inequality of age, since the average age of the three groups was remarkably uniform. Similar

Table IV Therapy and creatinine clearance

\begin{tabular}{|c|c|c|c|c|c|}
\hline \multirow[t]{3}{*}{ Therapy } & \multirow[t]{3}{*}{ Dosage } & \multirow{3}{*}{$\begin{array}{l}\text { Mean } \\
\text { age } \\
\text { (yrs) }\end{array}$} & \multicolumn{3}{|c|}{ Creatinine clearance } \\
\hline & & & \multirow[t]{2}{*}{ Normal } & \multicolumn{2}{|c|}{ Abnormal } \\
\hline & & & & No. & Per cent. \\
\hline \multirow[t]{3}{*}{ Salicylate } & None or & $52 \cdot 9$ & 16 & 16 & 50 \\
\hline & Moderate & $53 \cdot 2$ & 20 & 20 & 50 \\
\hline & High & 53 & 12 & 13 & 52 \\
\hline \multirow[t]{3}{*}{ Gold } & Full course & $56 \cdot 6$ & 13 & 12 & 48 \\
\hline & Part course & $57 \cdot 9$ & 4 & 5 & 55 \\
\hline & None & $52 \cdot 3$ & 31 & 32 & 50 \\
\hline \multirow[t]{3}{*}{ Steroids } & $>7 \cdot 5$ & $52 \cdot 4$ & 14 & 16 & 53 \\
\hline & $\begin{array}{l}\text { mg./day } \\
\text { Small }\end{array}$ & $52 \cdot 6$ & 4 & 5 & 55 \\
\hline & None & $53 \cdot 3$ & 30 & 28 & 48 \\
\hline
\end{tabular}


negative findings emerged from studies of other therapy, including gold and steroid hormones. Only nine patients had taken phenacetin-containing analgesic compounds regularly, and glomerular function in these patients was not significantly worse than in other groups.

The results confirm that the GFR falls with age and is lower in the female. No correlation was found with the duration of rheumatoid arthritis or with the height of the diastolic blood pressure. The more severe forms of rheumatoid disease, as judged by the presence of articular erosions and possibly of subcutaneous nodules, are associated with a greater incidence of impaired GFR, but salicylate, corticosteroid, and gold therapy appear to be of no importance in this respect.

\section{Discussion}

The fact that the GFR decreases with increasing age is well documented (Davies and Shock, 1950). In this study it has been possible to separate the factor of age from other possible aetiological factors by considering the average age of the various groups. The presence or absence of nodules and erosions was not related to any significant difference in age between the two groups, and this was also true for the various forms of therapy. Age can therefore be discounted in the consideration of the results.

Since the first report of a possible link between excessive ingestion of analgesics and renal disease (Spühler and Zollinger, 1953), numerous clinical and pathological studies both in humans and in animals have been carried out, and these have for the most part confirmed the association. The surveys of autopsy material by Lawson and Maclean (1966) and Burry, de Jersey, and Weedon (1966) revealed that there was a high degree of correlation between total doses of phenacetin-containing analgesics and the incidence of papillary necrosis. Lawson and Maclean (1966) noted an apparent excess of renal disease in rheumatoid arthritics treated with salicylates compared with controls, but were not able to give figures for the salicylate consumption of the controls. Experiments with laboratory animals, such as those of Saker and Kincaid-Smith (1969), have been unsuccessful in inducing papillary necrosis with even large doses of phenacetin alone, but these changes were induced readily by a commercial preparation of aspirin, phenacetin, and caffeine, and even by aspirin alone, particularly in conditions of dehydration. Scott, Denman, and Dorling (1963) have shown that salicylates increase the desquamation of epithelial cells, at least temporarily, and Prescott (1965) has drawn attention to the fact that salicylates have a greater ability to influence cell metabolism than phenacetin and may therefore have a greater propensity to induce toxic changes.
Sørensen (1960) was unable to show that patients who had consumed even large quantities of phenacetin had poorer glomerular function than controls, but did not study the effects of salicylates. The clinical series of Bulger and others (1968) showed a statistically significant increase in the incidence of renal abnormalities, including poor glomerular function, in patients with a larger total dose of salicylates, but the numbers studied were small. The disparity in duration of arthritis and presumably of treatment, and the absence of information concerning the severity of arthritis in the various groups, make any deductions concerning the effects of therapy questionable.

No such trend was shown by the present investigation. Although it is admitted that quantitation of a patient's intake of salicylate is extremely difficult except on a prospective basis, the failure to demonstrate any difference in GFR between the group taking no salicylate or occasional tablets only and the group taking large doses makes any causal relationship between salicylate therapy and abnormal glomerular function unlikely.

Negative results were also seen when correlation between impaired GFR and corticosteroid or gold therapy was sought; this finding is in agreement with the results of both Bulger and others (1968) and Sørensen (1960).

There is thus strong circumstantial evidence to support the contention that impairment of glomerular function is a result of rheumatoid disease and not the drugs given to treat the disease. Support is found in the strong correlation between the presence of articular erosions and possibly of rheumatoid subcutaneous nodules and impaired function. This finding agrees with the work of Sørensen (1960), who showed that the greatest severity and frequency of renal impairment was found in the group with the most severe disease.

Isolation of the precise pathological change causing the abnormality of glomerular function is extremely difficult. In this series a comprehensive set of investigations, including renal biopsy in eleven cases, produced some further information. Of the group of 49 with reduced function, six had bacteriuria, and Dontas, Papanayiotou, Marketos, and Papanicolaou (1968) have shown that symptomless bacteriuria is associated with a reduced GFR. Two patients had shrunken scarred kidneys as shown by intravenous pyelography. Of the eleven patients on whom renal biopsies were performed, two had atrophic glomeruli and the changes known as 'interstitial nephritis', two had atrophic glomeruli and arterial intimal hyperplasia, and one had amyloid infiltration. Two other cases with amyloid proven by renal biopsy had normal creatinine clearance values.

Thus 36 cases remain in which the pathological basis for disturbed glomerular function is unknown. It is possible that some of these patients may have 
analgesic nephropathy, since it has been shown by Dawborn, Fairley, Kincaid-Smith, and King (1966) and by Fairley and Kincaid-Smith (1967) that advanced papillary necrosis may be present without microscopic haematuria or pyuria and with a normal pyelogram. However, the failure to correlate renal impairment with salicylate or phenacetin intake in this series makes it unlikely that this is the case.

Various vascular abnormalities have been noted, of which the proliferative glomerulitis described by Baggenstoss and Rosenberg (1943) has subsequently been discredited by Brun, Olsen, Raaschou, and Sørensen (1965). The latter found some evidence of a focal hypercellularity of the tuft, but this finding awaits confirmation. Necrotizing arteritis is known to be rare. Bywaters (1957) described an obliterative endarteritis in patients with rheumatoid arthritis, subcutaneous nodules, and peripheral gangrene, and Mahallawy and Sabour (1959) reported similar appearances in five renal biopsies. Later investigators, such as Brun and others (1965) and Pollak, Pirani, Steck, and Kark (1962), noted obliterative vascular changes but ascribed them to arteriosclerosis. Nevertheless, an obliterative endarteritis limiting renal blood flow remains perhaps the most attractive of a number of alternative explanations for reduced glomerular function in rheumatoid arthritis.

\section{Summary}

In the course of a survey of the renal function of 97 unselected patients with classical or definite rheumatoid arthritis, the glomerular filtration rate was estimated by means of the endogenous creatinine clearance test.

In 49 patients the creatinine clearance was less than $80 \mathrm{ml} . / \mathrm{min}$. As expected, lower values were found in females and in older patients, but no correlation was seen with duration of disease. It was observed that patients whose disease was characterized by the presence of articular erosions had lower clearance values than the remainder, the difference being statistically significant and not explicable by difference of age or sex. A similar trend to lower clearance values was seen in patients with subcutaneous nodules.

No correlation was found between glomerular function and treatment with salicylates, gold, or corticosteroids.

It is concluded that impairment of glomerular function is an expression of rheumatoid disease.

My thanks are due to Dr. C. S. Ogg, Department of Nephrology, Guy's Hospital, and to Dr. M. Abrams, Department of Medicine, Guy's Hospital, for their invaluable assistance.

\section{References}

Baggenstoss, A. H., And Rosenberg, E. F. (1943) Arch. Path., 35, 503 (Visceral lesions associated with chronic infectious (rheumatoid) arthritis)

Brun, C., Olsen, S.. RaAschou, F., and Sørensen, A. W. S. (1965) Nephron, 2, 65 (Renal biopsy in rheumatoid arthritis)

Bulger, R. J., Healey, L. A., AND Polinsky, P. (1968) Ann. rheum. Dis., 27, 339 (Renal abnormalities in rheumatoid arthritis)

Burry, A. F., De Jersey, P., AND Weedon, D. (1966) Med. J. Aust., 1, 873 (Phenacetin and renal papillary necrosis: results of a prospective autopsy investigation)

Bywaters, E. G. L. (1957) Ann. rheum. Dis., 16, 84 (Peripheral vascular obstruction in rheumatoid arthritis and its relationship to other vascular lesions)

Davies, D. F., AND SHOck, N. W. (1950) J. clin. Invest., 29, 496 (Age changes in glomerular filtration rate, effective renal plasma flow, and tubular excretory capacity in adult males)

Dawborn, J. K., Fairley, K. F., Kincaid-Smith, P., AND KING, W. E. (1966) Quart. J. Med., 35, 69 (The association of peptic ulceration, chronic renal disease, and analgesic abuse)

Dontas, A. S., Papanayiotou, P., Marketos, S. G., and Papanicolaou, N. T. (1968) Clin. Sci., 34, 73 (The effect of bacteriuria on renal functional patterns in old age)

FAIRLEY, K. F., AND KINCAID-SmITH, P. (1968) Brit. med. J., 1, 156 (Renal papillary necrosis with a normal pyelogram)

HeidelmanN, G., Huth, J., AND Koch, E. (1956) $Z$. Rheumaforsch., 15, 208 (Über nierenfunktionsstörungen bei chronischer polyarthritis)

Lawson, A. A. H., AND Maclean, N. (1966) Ann. rheum. Dis., 25, 441 (Renal disease and drug therapy in rheumatoid arthritis)

Mahallawy, M. N. E., AND S Sabour, M. S. (1959) Lancet, 2, 852 (Renal lesions in rheumatoid disease)

Pollak, V. E., Pirani, C. L., Steck, I. E., ANd Kark, R. M. (1962) Arthr. and Rheum., 5, 1 (The kidney in rheumatoid arthritis; studies by renal biopsy)

PresCotT, L. F. (1965) Lancet, 2, 91 (Effects of acetylsalicylic acid, phenacetin, paracetamol, and caffeine on renal tubular epithelium)

RICHTER, A. (1942) Z. Rheumaforsch., 5, 187 (Die nierenfunktion bei progressiver chronischer polyarthritis)

SAKER, B. M., AND KINCAID-SMITH, P. (1969) Brit. med. J., 1, 161 (Papillary necrosis in experimental analgesic nephropathy)

Scott, J. T., DenMan, A. M., AND DoRling, J. (1963) Lancet, 1, 344 (Renal irritation caused by salicylates)

Sørensen, A. W. S. (1960) Acta rheum. scand., 6, 115 (Investigation of kidney function in rheumatoid arthritis)

SPÜhleR, O., AND Zollinger, H. U. (1953) Z. klin. Med., 151, 1 (Die chronisch-interstitielle nephritis) 